\title{
SIMBOOL EN WAARHEID
}

\section{NOG 'N MENING?}

Verskillende skrywers het hulle al uitgespreek oor die waarde van die simbool. Martin Foss maak die stelling: "We need a system of symbols ... this system is a ground on which we stand and has therefore to be regarded as a highly valuable treasure ..."1) Om simbole te ontbeer beteken vir hom "to plunge into the darkness of nothingness ..." (id, p 62). Elders word aan simbole die waarde en funksie van ' $n$ universele taal toegeken. ${ }^{2}$ ) Die uitgebreide literatuur oor hierdie onderwerp getuig egter van meer as net dit - dit getuig ook van die verskillende en uiteenlopende teorieë oor die simbool. Geen wonder dat A.G. Lehmann, na 'n ondersoek oor die Franse simbolisme, tot die volgende byna siniese gevolgtrekking kom nie: "We may end by seeing no more than a mass of opinion out of which the less responsible critic may produce very much what he chooses for a new fancy theory of art and 'impressionistic' histories of literature."3) Die ondersoeker wat dit as rede sou aan voer om hierdie onderwerp te vermy, sou sy taak om sentrale probleme op sy vakgebied vir sy tyd en situasie en vanuit sy beskouing oop te skryf ontduik. Eerder maak bewerings soos dié van $K$ von Delft dat simbole in die letterkunde van ons tyd ook in Afrikaans min daartoe bydra "om aan die mens van ons tyd die grondslag van sy Syn bloot te lê", ${ }^{4}$ ) besinning oor die simbool en sy funksie noodsaaklik.

\section{BASIESE BEGRIP}

Die waarde van die simbool berus op sy basies bipolêre karakter, wat ook etimologies in die woord simbool opgesluit lê. Die Griekse symbolon, waaruit die term afgelei is, dra die betekenis van waarmerk, oorspronklik 'n herkenningsteken in die vorm van twee helftes van dieselfde voorwerp wat by sluiting van 'n ooreenkoms geskei en later as bewys op mekaar gepas is.

Oordragtelik is die woord gebruik vir 'n gebeure of voorwerp wat na iets hoërs verwys, ${ }^{5}$ ) sodat die simbool 'n verwysingskarakter as basiese kenmerk het. In plaas daarvan dat die andersheid van die passende helftes lê in die andersheid of teenoorgesteldheid van die snit of breuk van die voorwerpe, lê dit nou in die bestaan van die twee helftes in verskillende sfere, nl. die empiriese en die ideële, bv. metafisiese, religieuse of abstrakte oor die 
algemeen, dit wil sê in die moontlikheid om die betekende of gesimboliseerde aan sy 'helfte' te herken. En aangesien die empiriese 'helfte' sintuiglik waarneembaar is, word dit simbool genoem van die vaer omlynde ideële 'helfte' waarmee dit geassosieer word, iets wat in sy eie reg bestaan maar die ideële by die waarnemer oproep, gewoonlik iets enkelvoudigs wat iets van groter kompleksiteit verteenwoordig.

\section{SIMBOOLINDELING}

Bogenoemde geld die simbool oor die algemeen - 'n begrip met 'n groot reikwydte, want dit kom voor as term in die logika, wiskunde, semantiek, epistemologie, teologie, politiek en die kunste. In al hierdie gevalle is die simbool 'n konkrete medium vir die hantering van die andersins ondeurgrondelike of moeilik hanteerbare. In der waarheid bestaan daar' $n$ groot verskeidenheid simbole. Binne die betekenisveld van die woord simbool is daar, na gelang van die konteks waarin dit gebruik word, etlike variante. 'n Wiskundige simbool is iets anders as 'n literêre simbool, ens. Daarom is dit nodig om tussen die verskillende soorte te probeer onderskei. As indelingsbeginsel kan die verhouding tussen simbool en gesimboliseerde dien. Omdat dit hier ook om simbool en semantiese aspek gaan soos by die transformasie-in-diewoord in die literêre werk, word hierdie verhouding gekenmerk deur die mate van noodwendigheid tussen simbool en gesimboliseerde. Langs die hele linie van simbooltipes (betekenisvariante van simbool) varieer hierdie verhouding van uiterste arbitrariteit tot uiterste noodwendigheid. Hiervolgens kan hoofsaaklik vyf tipes simbole onderskei word:

\subsection{WILLEKEURIGE SIMBOLE}

Hulle word veral gebruik op die gebied van die eksakte wetenskappe en die waarde van die simbool moet eksplisiet aangedui word, bv $X=-3$, voordat dit gebruik kan word. Die verhouding tussen simbool en referent is volkome kunsmatig, is individueel en willekeurig bepaal, en konvensie speel geen rol nie.

\subsection{ARBITRER-KONVENSIONELE SIMBOOL, SOOS} DIE WOORD

Alhoewel die verband tussen simbool of woordteken (klanklaag) en betekenis arbitrêr is, berus dit op konvensie en is dit meer 'permanent' as dié in die vorige. 
In sy buiteliterêre gebruik word die woord ook gewoonlik nie simbool genoem nie maar teken.

\subsection{TRADISIONELE SIMBOOL}

Hier is die verhouding tussen simbool en gesimboliseerde minder arbitrêr as by die vorige. Die gesimboliseerde is al minder skerp omlyn. Die kruis is só simbool van die Christendom of lyding of selfs Christelike geloof. Hier word die verhouding dus al gekenmerk deur 'n mate van noodwendigheid omdat hierdie sake in roue verband met hulle 'betekenisse' staan. So is die Nagmaalwyn en die brood simbole. Maar die mate van arbitrariteit wat dié simhole kenmerk, blyk daaruit dat hulle waarde afhang van 'n bepaalde situasie of konteks. Weg van die Nagmaalstafel kan brood weer net brood wees of simbool van blote voedsel, en wyn weer net wyn, behalwe wanneer dié woorde in ' $n$ bepaalde konteks, byvoorbeeld in 'n gedig voorkom. Dit is ook goed illustreerbaar met 'n onlangse aktuele uitspraak van André P Brink: "To an overwhelming majority of people who have never read a single line of his verse, Breyten is a symbol of resistance to oppression. Among Africans, Coloureds and Indians he has become a symbol of hope."6) Dieselfde persoon sal vir die "bevoorregte wit enklave' 'n totaal ander simboliese waarde hê en vir die oningewyde niks beteken nie. Alhoewel die assosiasie tussen simbool en gesimboliseerde in hierdie geval deur tradisie tot stand gebring word, maak kommunikasiemedia dit moontlik dat dit oornag kan plaasvind, soos met die onlangse boekverbod geblyk het. Hierdie soort simbole kom veral voor op godsdienstige en politieke gebied en het 'n soveel dringender appel omdat dit te doen het met geloof, sentiment, ideologie, idealisme, eiebelang en voortbestaan, en die rasionele of nugtere so 'n geringe rol daarby speel. Soos die pas genoemde konvensioneelarbitrêre simbool, nl. die woord, bestaan hierdie soort simbool buite die literêre werk maar kán dit daarin óók tot simbool gemaak word, soos D J Opperman die tradisionele simbool springbokke binne die konteks van sy gedig met dié titel in DOLOSSE omskep tot literêre simbool: 


\title{
Springbokke
}

\author{
Astrale magte op hul bloed \\ en soute in die grasse het bepaal \\ dat uit woestyn en vlakte \\ hulle as één groot trop ontmoet \\ en dae lank eers in 'n stofwolk maal \\ tot een meteens koers snuif wat almal vat \\ en dan geen weerstand duld \\ dreunend oor veld en bult \\ waar hoef en horings alles plat \\ trap en voor hul vaart wegvaag, \\ elkeen gewillig om sy lyf te gee \\ dat die trop oor slote en riviere jaag \\ en onkeerbaar afstort in die see: \\ "Ons is geroepe om 'n groot afspraak \\ met die dood te maak."
}

\section{J Opperman (DOLOSSE)}

Slegs die slot van die gedig gee wending aan die tradisionele beeld van die trekkende springbokke, en wel deur die oordrywing van hulle 'besetenheid', wat hulle in die see laat stort soos die besete varke van Gadara. Dit gee onmiddellik aan die springbokke en hulle stormloop 'n 'menslikheid', sodat hierdie neiging en gebeure geldig word vir 'n groep mense wat met springbokke geassosieer word: Suid-Afrikaners? Die menslikheid van die trop word bevestig in hulle wanhoopskreet, en die ons identifiseer dié massa nader. In hulle selfmoordstormloop simboliseer hierdie springbokke juis die histeriese massa wat, asof deur "astrale magte" (van ideologie, tradisie of idealisme maar beslis dwaas!) die koerssnuiwende leier teen alle weerstand in tot in die dood volg. So 'n vertolking word in hierdie geval ook gesteun deur die ander mens-dier-gedigte met beslis baie sterk onderlinge verwysings waartussen Springbokke geplaas is, en dit in 'n bundel wat 'n baie hegte eenheid vorm.

\subsection{DIE NATUURLIKE SIMBOOL}

Dit is die buite-estetiese simbool wat gekenmerk word deur die noodwendigste verband tussen simbool en gesimboliseerde. In Shipley se DICTIONARY OF WORLD LITERATURE ( $p$ 405) word die roos, wat vir Engelsman en Chinees albei soet ruik en mooi is, as voor- 
beeld genoem van die universele 'taal' waarin daar deur middel van natuurlike simbole 'gespreek' kan word. Dat dit so is, veronderstel dan dat daar twee analoë werklikhede bestaan wat onderlinge verwysing moontlik maak. Die verband tussen hierdie simbool en gesimboliseerde is 'n 'gegewe' verhouding oor die noodwendigheid waarvan daar min twyfel kan bestaan. Alhoewel hierdie simbool nie in die eerste plek in estetiese konteks bestaan en nie van so'n konteks afhanklik is nie, kan dit ook binne 'n kunswerk gebruik word.

\subsection{DIE ESTETIESE SIMBOOL}

Dit word gekenmerk deur die hoogste mate van estetiese noodwendigheid tussen simbool en gesimboliseerde. Hierdie verband is so anders as wat die geval by ander sonrte simbole is dat dit dikwels in oordragtelike sin met die magiese geassosieer word. Behalwe in die letterkunde en in die besonder in die poësie, word hierdie verband ook in byvc orbeeld die beeldenrie kunste met verskillende estetiese middele tot stand gebring. In die woordkunswerk is hierdie medium die woord met al sy aanwendingsmoontlikhede.

\section{LITERERE SIMBOOL}

Wat die literêre simbool betref, moet goed in gedagte gehou word dat, behalwe dat dit behoort tot 'n estetiese wêreld, dit in die woord gedra word, in verband staan met die semantiese aspek daarvan, sodat simboliek inderdaad 'n ekstra semantiese dimensie van die woord word. As mees komplekse tipe simbool en wat behoort tot die kuns wat met die mees bekende medium werk, leen die literêre simbool hom die beste tot 'n uiteensetting wat lig kan werp op die gesimboliseerde as waarheid. Ter wille van nadere afbakening van die begrip literêre simbool moet dit nog gekonstrastreer word met ander literêre beelde. Juis die bogenoemde komplekse verband tussen simbool en gesimboliseerde onderskei dit van die metafoor en eenvoudige vergelyking. "A metaphor", sê Olsen, "is only the name of a certain thing transferred to its similar in respect to a certain similarity, although their concepts remain distinct." $)$ Dit berus dan op die enkele tertium tussen die twee geassosieerde sake, soos die enkele ooreenkoms tussen beminde en plante in Hooglied 1:13, 14: "My beminde is vir my ' $n$ bossie mirre wat tussen my borste rus. My beminde is vir my 'n bossie hennablomme in die wingerde van Engedi." Ook die verskil tus- 
sen simbool en allegorie staan in verband met hierdie kompleksiteit, aangesien 'n allegorie slegs 'n uitgebreide metafoor is. Dit is slegs tweedimensioneel, en 'n verhaal is allegories as ' $n$ tweede betekenis parallel daarmee gelees kan word.

So is die visioen van die vrou en die draak (Openbaring 12) en van die groot hoer wat deur die dier verlei is (Openbaring 17) allegorieë, en die vier perde van Openbaring 6 allegoriese figure. Daarteenoor eis die simbool in eie reg die aandag op, soos die springbokke in die genoemde Opperman-gedig.

\section{HISTORIES}

'n Selektiewe historiese beeld van die benadering van die simbool werp lig op die verhouding tussen simbool en waarheid. "The establishment of a dialectical and symbolistic view of poetry," sê R Wellek, "grows out of the organic analogy, developed by Herder and Goethe, but proceeds beyond it to a view of poetry as a union of opposites, a system of symbols." ${ }^{\prime 9}$ ) Goethe, wat ware simboliek sien as lewendige, onmiddellike openbaring van die algemene in die besondere, spreek hom al uit oor simbool en waarheid: "Das Wahre, mit dem Göttlichen identisch, lässt sich niemals von uns direkt erkennen, wir schauen es nur im Abglanz, im Beispiel, im Symbol, in einzelnen und verwandten Erscheinungen; wir werden es gewahr als unbeschreibliches Leben und können dem Wunsche nicht entsagen, es dennoch zu begreifen." ${ }^{10}$ ) En die simbool is vir die romantiese kritici die vereniging van dramatiese teenstellings uit die potensieel ryke baaierd, die kosmiese chaos, soos F Schlegel dit sien. Volgens A W Schlegel word die oorspronklike simboolgebruik van die taal in die simbool herstel, sodat in die poësie die taal sy arbitrêre karakter verloor, en so word die waarheid geopenbaar: "In jenen schrankenlose Übertragungen des poetischen Stils liegt ..., der Ahndung un Anforderung nach, die grosse Wahrheit das eins alles und alles eins ist." "1) Raidt toon aan dat hierdie idealistiese teorie dat alles kan beteken in in die kunsopvatting en simboolgebruik van ons eie D J Opperman met sy 'uitbuiting' van woordmoontlikhede 'n weerklank vind ${ }^{12}$ ) -'n aanduiding dat die Schlegelteorie die grense van sy tyd ver oorskry het, onder andere omdat in ooreenstemming met die romantiese wêreldbeskouing, simboolgebruik die bestaan van 'n werklikheid benewens die sigbare impli- 
seer. 'n Ander romantikus, Coleridge, lê klem op die deursigtigheid van die simbool: "A symbol is characterised ... above all by the translucence of the eternal through and in the temporal. It always partakes of the reality which it renders intelligible; and while it enunciates the whole, abides itself as a living part in that unity of which it is a representation." ${ }^{13}$ ) Raidt wys daarop dat die simbool vir die meeste romantici deel van hulle wêreldbeeld was, sodat die literêre kunswerk 'n tweede wêreld geword het, 'n naskepping van die goddelike Skepping deur die god-digter. ${ }^{14}$ ) Sy wys op die moderniteit van hierdie opvatting van die gedig as wêreld, wat ooreenstem met die "New Criticism" se siening van die gedig as selfgenoegsame wêreld of 'concrete universal'. Een van die geldigste implikasies van die romantiese simboolopvatting in die breë is dat daar blykbaar 'n verband aanvaar is tussen simbool en die 'wêreld' van die kunswerk.

In die ketting van beskouings van en houdings teenoor die simbool vorm die Realiste, in besonder die Naturaliste (einde 19de eeu) 'n belangrike skakel. Hulle vind geen nut vir die aanvaarding van "a superior world above the senses" nie, omdat die waarheid vir hulle nie daar lê nie. Bowra stel dit so: "They had a stern conviction that what mattered was truth and that truth could be found empirically in this world." ${ }^{15}$ ) Dit is 'n goeie aanduiding van die houding van 'n geslag wat hulle op die onmiddellike werklikheid (diesseits?) rig, se houding teenoor die simbool.

Teen hierdie Realisme het die Franse Simboliste in opstand gekom met hulle aanvaarding van "an ideal world which was, in their judgement, more real than that of the senses." ${ }^{16}$ ) Van hulle het Baudelaire se simbole nog die kwaliteit van die romantiese simbole, maar Mallarmé en sy volgelinge, vir wie die Absolute in die Skone lê, probeer om bonatuurlike ervaring in die taal van sigbare dinge gestalte te gee, en amper elke woord word gebruik ter wille van die assosiasies van 'n werklikheid bokant die sintuiglike wat dit oproep - 'n metode wat eie is aan apokaliptiese gedigte soos dié van William Blake en mistieke poësie. Omdat die simbolis die ekstase wat met die gebed en oorpeinsing vereenselwig word vir die digter in die beoefening van sy vak opeis, kom die estetiese baie na aan die religieuse, soos in die poësie van Sint Jan van die Kruis. ${ }^{17}$ ) In hierdie kuns gaan dit om die nie-empiriese. 
Die empiriese verskynsels is slegs konkrete dinge wat die onsigbare, wat grensloos ryk is, voorstel. Dit lê ook Mallarmé se teorie ten grondslag, naamlik dat die poësie nie moet meedeel nie, maar suggereer en oproep deur atmosfeer te skep. Daarmee word weer eens waarde toegeken aan die geheel van 'n literêre werk. Maar die simboliste inisieer ook die individuele simbool. Terwyl Baudelaire simbole van die katolisisme (dus tradisionele) in sy poësie gebruik, vind Mallarmé sy eie, wat sy poësie duister en moeilik maak. Maar aangesien dit vir hom gegaan het om sy eie visioene, ontdek hy die rykdom van die self as onderwerp van die poësie. Daarmee is 'n baie belangrike dimensie tot die beheersingsveld van die digter toegevoeg, naamlik die self, en steek die probleem van die individuele simbool ("le symbolisme qui cherche") wat vertolkbaarheid én norm betref, kop uit. Die digter praat nie meer vir/met 'n gemeenskap nie maar vir/met homself, en put sy simbole uit sy eie indrukke. ${ }^{18}$ )

$\mathrm{T} S$ Eliot praat in 1932 in ooreenstemming met die opvatting van $C G$ Jung van die digter se "recurrent images, which may have symbolic value, but of what we cannot tell, for they have come to represent the depths of feeling into which we cannot peer." Volgens hom "the prelogical mentality persists in civilised man, but becomes available only to or through the poet." ${ }^{19}$ ) Die grondslag hiervan is die Jungiaanse stelling dat onder die persoonlike onbewuste, dit wil sê die 'vergete' neerslag van ons verlede, daar 'n kollektiewe onbewuste of onbewuste neerslag van ons rasseverlede of selfs ons voormenslike verlede is. Hiervolgens bestaan simbole binne ' $n$ patroon in 'n mite, wat sedert die oertyd van die mens se bestaan geskep is. Die onbewuste moet dus selfs vandag nog besig wees om simbole met universele waarde voort te bring. So 'n simbool dra dan in die 'lewende mite, daartoe by om ' $n$ volk te rig en te laat voortbestaan; dus leef die mens as't ware deur sy tot mite geordende simbole. By 'n vernuwing word psigiese energie getransformeer tot 'n beeld of figuur wat in die buitewêreld lewensinhoud kry, sodat die ware simbool (deel van die 'lewende' mite) verwys na iets wat verborge is, iets wesenliks wat nie gedefineer kan word nie en waarvoor daar 'n teken nodig is om dit aan die mens te openbaar. Deur die simbool, wat in die diepste lae van die kollektiewe onbewuste deur argetipes gevorm word, "the world itself is speaking" ${ }^{20}$ ) 
en word die ongedifferensieerde, 'lewende' inhoud uit die kollektiewe onbewuste gedifferensieer tot die besondere tyd of plek waarin die mens hom bevind. Hierdie transformasie-in-die-simbool vind ook plaas ooreenkomstig psigologiese inhoude eie aan die menslike ras, gebaseer op die verhouding van die mens tot die kosmos - iets wat grens aan die metafisika. Psige en wêreld is dan so nou verbonde dat die psige 'die wêreld self' word. Die simbool as deel van die mite is dus eintlik skakel tussen individu en heelal. Daar moet telkens, wanneer ou simbole hulle inhoud verloor het, nuwe ware simbole gevind word. In hierdie proses het die skrywer'n belangrike aandeel deur alle moontlike materiaal uit die onbewuste te voorskyn te bring. Die waarheid of onwaarheid hang van God en die ywer van die skrywer af. Die belangrikste en mees bruikbare aspekte van hierdie teorie, soos deur Etienne Leroux aanvaar, is dat die simbool by implikasie transformasiemiddel van die geopenbaarde is; dat die openbaring in die simbool van lewensbelang vir' $n$ betrokke gemeenskap is en dus 'n openbaring moet wees van die ware en ook dat dit betrekking het op die kosmos, dit wil sê die empiriese wêreld en sy samehang. Die noodwendigheid om nuwe simbole te vind word hier - binne die strekking van die teorie - sinvol gemotiveer met 'n eie opvatting van die gevaar van 'n 'dooie' mite, dit wil sê ook 'dooie' simbole waarvan hierdie mite ' $n$ patroon is.

'n Uitspraak wat die historiese ontwikkeling van die simboolbeskouing oorkoepel, vind 'n mens in die stelling van Von Wilpert: "Die gehaltlichen Funktionen des Symbols wechselt mit dem Gestaltungsziel der Epochen: im Mittelalter als Heilswahrheit und göttliche Weltordnung, im Sturm und Drang als Kraft, in der Klassik als Tiefe, in der Romantik als Unsagbare, im modernen Symbolismus, der das Symbol zum bewussten Gestaltungsziel erhebt, als Ichaussprache der einsamen Seele, geheimnisvolle Lebensgefühls und persönlichen Erlebens." ${ }^{21}$ ) En na die simbolisme? Om daaraan aandag te kan gee en moontlik die dilemma aan te raak wat vroeër in verband met die simbool genoem is, moet eers aan die hand van spesifieke voorbeelde stelling in verband met die wese, kenmerke en funksie van die simbool ingeneem word.

\section{SIMBOOL EN 'CHAOS'}

Dis byna vanselfsprekend dat die simbool gegenereer word in wat Van Vlierden in verband metdie roman noem 
die gesprek met die werklikheid in die 'skeppende' bestaan van die mens, ${ }^{22}$ ) dit wil sê in die woordkunstenaar se konfrontasie met sy beheersingsveld, wat dikwels 'baaierd' of 'chaos" genoem word. Die noodsaak tot kunsmaak by die digter skryf Van Vlierden toe aan die "volte en leegte" van hierdie chaos: "Hij moet scheppen, wordt aangespoord tot scheppen vanuit de volte van de chaos, wordt uitgedaagd om te scheppen vanuit de leegte van de chaos." ${ }^{23}$ ) In verband met die simbool sou 'n mens die 'volte' van die chaos kon sien as die moontlikhede van die oorweldigende empiriese verskynsels, dit wat uiteindelik simbool kan word, en die 'leegte' as die vraag na die samehang, sin of bestemming van hierdie dinge. In die simbool word immers singelade kerne hiervan binne 'n estetiese denksisteem vasgevang. Dit bring juis vanweë die reikwydte daarvan 'n deurbreking van die grense van woord en sin.

Vir die transformasie van so 'n sinkern wat voldoen aan die eise van noodwendigheid in die woordkuns moet die mens in sy skeppende bestaan ' $n$ middel vind. Soms gee 'n digter in sy verse verslag van so 'n soeke, soos die geval is in $\mathrm{D} \mathrm{J}$ Opperman se veel gesiteerde Wildernis, waaril hy die soeke na 'n 'besweringsmiddel' (simbool) vir die eensaamheid soek:

"Watter boom se bitter wortel, watter beentjie van die tortel

sal die hart teen bose gees beskerm en van eensaamheid genees?

sal die kranse en die wildepeer tot sin en ewigheid besweer?"

En uiteindelik die vonds van die middel met genoeg suggestiwiteit en algemene geldigheid:

"buite agter 'n miershoop lê/die maer lyk van Eugene Marais.”

'n Mens vermoed iets van hierdie fase in die simboliseringsproses ook in die soeke van klip na klip in sy Man met flits en die watersoektog van die naaldekoker in Opperman se gedig met dié titel. En van die onverwagsheid en nuutheid van die simboolvonds spreek sy 
gedig Mériba. By die sug na dinge waarvan die volk kan lewe, vind die digter-Moses onder die genade en straf van God vir hulle nie die oorvloed nie maar die ware:

\footnotetext{
"Maar onder my staf

wat driftig spreek

dat, soos uit 'n kraf

$U$ vryelik breek
}

uit die rots, uit die ding,

in Kades, die stad

op die sande van Sin,

breek $U$ waters brak."

Dat in hierdie gedig iets meer lê as die historiese gebeure blyk uit die "spreek" van die staf in plaas daarvan dat daarmee geslaan word. Ook die verswyging van die naam Moses dui op 'n aanspraak op groter geldigheid. Volgens hierdie werkwoordgebruik word die hele moontlikheid van die toepassing van die Mériba-gebeure op die digproses oorgedra. Die staf stem ooreen met die digterlike toerusting, die rots, die ding met die ontologiese verskynsels, terwyl "driftig" behalwe 'kwaad' ook 'vol drif, inspirasie" kan beteken - dit terwyl die "sake" van dié woorde ${ }^{24}$ ) ook nog bly wat dit op die konjunkte betekenisvlak is. Deur die assosiasie met dinge van die woordkuns word 'n 'woordkunsbetekenis' ook op " $U$ waters" oorgedra, en kry dit 'n metabetekenis van 'iets wat die digter met sy toerusting en skeppende werksaamheid van die werklikheid afding vir die volk om by/van te lewe', dit wil sê die waarheid met as kernbegrip duursame, vaste, standhoudende. "Brak" kry dan die metabetekenis van 'wrang', sodat in "brak waters" 'n paradoks opgesluit lê. Behalwe dat die digter aangewys is op so ' $n$ brandskatting van die woord in die gedig. "where all the elements are employed in such a way as to suffer a transformation into something more than their simple, abstracted, and dictionary selves," ${ }^{25}$ ) is dit 'n manier van openbaring van die komplekse, algemeen geldige. ${ }^{28}$ ) Susanne Langer noem dit die primitiewe funksie van die simbool: "To formulate facts and the fact-like elements of thought called 'fantasies'. This function is articulation." ${ }^{27}$ )

Noukeuriger beskou ontstaan met die situasieverandering van die historiese sfeer tot dié van die gedig- 
maakproses deur die gebruik van "spreek" binne die konteks van die gedig dus 'n nuwe, ongewone, abstrakte, veel ryker, selfs vaag omlynde betekenisvariant wat so seer anders is as die konjunkte betekenis, dat by implikasie na 'n nuwe saak/referent op 'n ander kenvlak verwys word. En dit word alleen deur die konteks tot stand gebring. Binne die konteks van die gedig word die raakpunte (tertia) tussen die twee sake ontgin, soos hier in die waters die lewegewende eienskap, die 'onaangenaamheid', die oorsprong uit die drif, die verband met God gevind word. Dit blyk ook by simbole soos "God se konka" in Opperman se Nagwag ${ }^{28}$ ) en dié in Paddas en Van Wyk Louw se Die beiteltjie. ${ }^{29}$ )' $n$ Aanduiding van die waarheidontginnende funksie van die simbool is daarin te vind dat in die oeuvre van 'n digter dikwels 'n simboolsisteem gebou word, iets wat voortkom uit sý wêreld en tot die mense van sy tyd spreek; dus 'n soort taal wat eie is aan en tyd en digter. Voorbeelde hiervan is Opperman se hantering van die ding en die ontwikkeling daarvan tot literêre 'dolos' ${ }^{30}$ ) en Van Wyk Louw se aanwending van die woord 'duister'. ${ }^{31}$ )

\section{SIMBOOL EN REALISME}

In Mériba en Nagwag wat hierbo genoem is, staan die simboliek nog in verband met die metafisiese. In die jonger poësie van D J Opperman en in Breyten Breytenbach se Nuwe Realisme is daar egter 'n sterker gerigtheid op die sintuiglik waarneembare. Dit raak ook die simbool as middel waarmee tradisioneel na 'n ander bestaansvlak verwys is. Steekproewe uit die poësie van hierdie twee digters kan ter illustrasie dien.

By Opperman kan skaars 'n beter voorbeeld gevind word as die hoogtepunt in die simboolontwikkeling in sy nuwer poësie, naamlik sy gebruik van die 'dolos' as simbool in Wensbeentjie (DOLOSSE, 1963). Die wensbeentjie as oorblyfsel wat tradisioneel in die wensproses gebruik word om die toekoms te peil, word in die konteks van dié gedig in 'n etenstafelsituasie gebruik om na drie dimensies van die menslike bestaan te refereer. Die situasie word heel eenvoudig geteken:

"Met alles afgepeusel/tot die been/wat sit ons nog/en beusel/nahongerig byeen?" 
Eerstens behou die woord "wensbeentjie" in die titel sy konjunkte betekenis. Nadat alles, alle vleis afgepeusel is tot die been, word daar met een van die bene wat oorbly, die wensbeentjie, ná 'n gesprek aan tafel, gewens. In plaas daarvan dat die been breek in 'n lang en kort kant soos gewoonlik, versplinter dit heeltemal. Een van die wensers maak dit oënskynlik speels af: "Dis tyd vermors./Ons bly twee stuks:/die mik verruk .../tot skerp, bros/splinters van geluk."

Hierdie slotstrofe kan steeds gelees word as die verslag van die breek van die wensbeentjie, wat vroeër met die woorde "span en ... breek" voorberei is. "Geluk" beteken dan dobbelaarsgeluk en "verruk" ' $n$ intensiewe vorm van 'ruk', net soos 'verbrou' 'n intensief van 'brou' is. Op die tweede betekenisvlak gaan dit om die spel tussen mens en mens, wat uitloop op vereensaming. Die tweede strofe in die uitbeelding van die wensery aan etenstafel verraai dit: "Die diepste wens/onuitgespreek, sal ons ten slotte/mens teen mens/span en ... breek."

Die lewe van die twee ontredderde mense wat in hierdie situasie bymekaar is, is "afgepeusel/tot die been" omdat hulle diepste wens onuitgespreek bly en omdat hulle "mens teen mens/span en ... breek."

Onuitgespreekte wense en onderlinge stryd (aanduidings van eensaamheid en liefdeloosheid) kenmerk dan dié verhouding, sodat mens en medemens onverenigbaar is. Die sterkste aanduiding is te vind in die slotstrofe: "ons bly twee stuks". Die rede vir die tweespalt (wat 'n raakpunt het met die twee 'takke' van die wensbeentjie) word in die gedig vergestalt in die dialoog wat die fatalis, wat in die eerste en laaste strofe (hierbo gesiteer) aan die woord is, voer met die beoefenaar van naasteliefde, wat die verskeurdheid wil oplos met selfverloëning: "Jý wens mý wens,/ek jóue word vervul."

Hier word die wensbeen, met sy tweepoligheid as raakpunt, simbool van die menslike verhouding, waarin persoonlikhede en selfs wêreldbeskouings bots, dus eintlik van die gaping tussen mens en medemens.

'n Laaste saak waarna die wensbeensimbool in hierdie konteks kan refereer, is die seksuele, wat in die slotstrofe 
met "die mik (wat) verruk" opgeroep word. Die woord "verruk" het immers die betekenis van 'sinnelik verruk'. Teen diè agtergrond kan "nahongerig byeen", "die diepste wens/onuitgespreek" en "mens teen mens/span en ... breek" verwys na 'n oppervlakkige seksuele belewenis. "Alies afgepeusel/tot die been" is dan 'n beskrywing van die leegheid van 'n ervaring wat vars in die geue is. Dan kan die slotreël van die gedig gelees word as 'n veralgemening, naamlik dat súlke sinnelikheid net "splinters van geluk" kan bring en nie durende geluk nie.

Hierdie hantering van die simbool deur Opperman kan as niks anders bestempel word nie as 'n digterlike kragtoer, waarin met die suggestieryke woord verskillende semantiese moontlikhede van 'n empiriese gegewe gelyktydig binne die gedig geaktiveer word. En die betekenisse wat hierdie simbool uitwaaier, is wáár, algemeen geldig en aktueel. Gesteun deur gebroke ryme en halfryme word die totstandbrenging van die simbool binne hierdie gedigkonteks 'n voortreflike voorbeeld van hoe die simbool fungeer in die 'aflees' van die ware uit die empiriese werklikheid.

Waar Wensbeentjie aanduiding is van die gebruik van ' $n$ simbool sonder metafisiese referensie, bied Breytenbach se Ikoon 'n sekere ontkenning van die metafisiese wat op die uiterste 'n aanduiding kan wees van die soeke na die metafisiese in die sintuiglike ervaring: $:^{32}$ )

dieper agter donker lae van velgeworde olie plat gesmeer teen 'n houtpaneel

gloei 'n ingelegde wêreld

bewaar in sy bloed soos perskes in hul stroop

en omdat alle volbringing gesuspendeer is is die aksie puur en rou afgeskil

tot sinlose stellings (koekoekklokke in 'n ruimteskip)

:in die voorgrond byt mense mekaar se strotte uit die boë bloed hang verstyf in die leegte blomknoppe sonder stingels die pyn onder tande sal eentonig bly priem; 'n soldaat staar met peulende oë na 'n soplepel voor sy neus; 'n wolk buig sy skouers in versteende afwagting; ' $n$ mier beur teen die verswikking van sy kuite; 
bo dit alles pryk 'n spykerige jesus teen 'n kruis sonder 'n gejanfiskaalde mossie se hoop op ontbinding, met 'n gryns tussen baardhare;

dieper agter vir ewig net buite bereik (soos marylin monroe)

rys 'n leë koel graf

(DIE YSTERKOEI MOET SWEET, 1964)

Afgesien van die ontwyding wat kenmerk is van hierdie heiligeportret in teenstelling met die Middeleeuse en selfs tradisionele heiligeportrette, ${ }^{33}$ ) is hierdie gedig 'n aanduiding van hoe Breytenbach die simbool wél gebruik. In die "ingelegde wêreld" in olieverf op 'n houtpaneel en wat ook 'wêreld' van die gedig word, is, in teenstelling met die vloeibaarheid wat gewoonlik die poësie van Breytenbach kenmerk, 'n beeld van gesuspendeerde volbringing (volgens die eksplisiete getuienis van die gedig) vasgevang. Die stelling "dat alle volbringing gesuspendeer is", kry gestalte in die onvoltooide handelings: die verstyfde bloed, die etende soldaat, die wagtende wolk en die beurende mier, met as klimaks die hangende "jesus", gesien op dieselfde vlak as al die werklikheidsdinge maar "sonder ... hoop op ontbinding," dus minder as die Bybelse mossie. Hierdie onvolkomenheids begrip word deur die konteks oorgedra op die "leë koel graf" wat op die agtergrond van die fresko sigbaar is. Daarmee word die leë graf, wat vir die Christen tradisioneel simbool is vir die oorwinning oor die dood en dus simbool van hoop, 'vernuwe' tot simbool van onvolkomenheid. In plaas daarvan dat dit gelaai word met 'n algemeen geldige waarheid, word dit gelaai met iets wat net vir die digter-eksegeet waar is en vir die Christen selfs meer as onwaar, naamlik anti-waar. Dit toon ook duidelik die vergestaltingsdoel van hierdie poësie, naamlik die ontdekking van die "verste en vreeslikste moontlikhede van die realiteit binne-in homself", met dié uitgangspunt: "die aarde behoort aan die mens/en die mens is aarde s'n" (Breytenbach: Aandmense, KOUEVUUR, 1969). Hierdie poësie is die resultaat van die aanvaarding van die taak van die digter soos Heidegger dit stel, naamlik "das stiftende Nennen des Seins und des Wesens aller Dinge". Omdat die aarde deur die woord ontdek word en dus eers deur die woord gestalte kry, skep 
die digter sy eie wêreld; vandaar die uiters persoonlike assosiasies van die woord en ook van die simbool, wat weens die hedegerigtheid dikwels verskraal tot 'n soort metafoor, bv. in laasgenoemde gedig: "al ... die dinge om my is onvrugbare minnaars". By veelvuldige gebruik groei so 'n metafoor in die poësie van Breytenbach tot simbool maar dan eerder op grond van herhaling, waardeur as't ware 'n individuele tradisie geskep word. 'n Simbool wat só tot stand kom, herinner aan wat Wellek en Warren van die simbool sê: "An 'image' may beinvoked once as a metaphor, but if it persistently recurs, both as presentation and representation, it becomes a symbol, may even become part of a symbolic or mythic system." "36) Voorbeeld hiervan is die telkens terugkerende voëlsimbool in Breytenbach se LOTUS (1970) en die wond as simbool van lewe, soos blyk uit Walvis in die berg (KOUEVUUR) en Drome is ook wonde (DIE HUIS VAN DIE DOWE, 1967), waarin wonde geassosieer word met bloed wat blom maar ook met die "borreling van liefde":

“... die wonde genees nie

die donkerste bloed bly blom

boorde van revolusies oor die laken

of die borreling van liefde in tuine

van wonde wat nie genees nie."

Soos wat in verband met die 'dolos'-simbool in die poësie van Opperman merkbaar is dat sekere metasemantiese waarde aan 'n bepaalde element binne die konteks van die gedig toegeken word, kry laasgenoemde woorde ook binne 'n sisteemskeppende geheel, al is dit groter as die gedig, die funksie van 'n middel tot transformasie van semantiese kerne binne 'n denksisteem.

Duidelik blyk dit dat 'n beperking van blik die kompleksiteit van die simbool beïnloed en trouens laat inboet aan noodwendigheid van die verband tussen simbool en gesimboliseerde, sodat die waarheidsbeeld wat die digter daarmee van sy wêreld bou, só individueel is dat dit daartoe neig om, ten spyte van die vlakheid daarvan (of juis daarom?), eerder te verduister as om te openbaar. Dat dit egter vir die digter as begenadigde skerper waarnemer en denker hoogs individuele middel word om 'n greep op die sin van sy wêreld te kry, staan vas. 


\section{VERNUWING}

Die mens, en ook die kunstenaar, het steeds die vastigheid van simbole nodig in die konfrontasie met sy wêreld - of dit nou die sterre is of klein stukkies realië of been uit sy omgewing, soos in die poësie van Opperman, en of dit wonde is soos by Brey tenbach. Steeds nuwe simbole moet gevind word en word gevind as deel van die voortgesette algemene openbaring, omdat ons wêreld steeds verander. Maar nuwe simbole word juis gesoek omdat oues nie meer die waarheid dra vir 'n bepaalde geslag en situasie nie, want "as daar geen openbaring is nie, verwilder die volk" (vgl Spreuke 29:18). Daarom word dit problematies as nuutgevonde simbole té individueel word, in so 'n mate anti-waarheid dra dat openbaring téénoor Openbaring te staan kom.

D H STEENBERG PU vir CHO 


\section{VERWYSING}

1. M Foss, Symbol and metaphor in human experience. Princeton 1949, p 102 .

2. J T Shipley. Dictionary of world literature. Totowa 1964, p 408.

3. A G Lehman. The symbolist aesthetic in France 1885-1895. Oxford 1968, p 317.

4. K von Delft. Simboliek en simbolisme - die dilemma van die moderne literatuur. Bloemfontein 1971, p 17.

5. Vgl G von Wilpert, Sachwörterbuch der Literatur. Stuttgart 1964. p 691 .

6. A P Brink. Some aspects of culture and apartheid. In Anatomy of apartheid, Spro-cas publication No 1. Johannesburg 1970, p 42.

7. E Olson. A dialogue of Symbolism. In R S Crane (red), Critics and criticism. Chicago 1957.

8. E Raidt. Opvattings oor die literêre simbool - van F Schlegel tot D J Opperman. In Kriterium 1, 2, Julie 1963, p 3.

9. R Wellek. A history of modern criticism: 1750-1950. Vol II, London 1966, p 3.

10. J W Goethe. Versuch einer Witterungslehre, aangehaal deur Von Delft. Op cit, p 6. Vgl. ook sy uiteensetting daarvan.

11. Wellek, Op cit, p 356.

12. Raidt, Op cit, p 4.

13. Aangehaal deur W Y Tindall, The literary symbol. New York 1955 , p 113.

14. Raidt, Op cit, $\mathrm{p} 5$.

15. C M Bowra, The heritage of symbolism. New York 1967, p 2.

16. Id, $\mathrm{p} 3$.

17. Id, p 5

18. Id, $\mathrm{p} 7$.

19. Aangehaal deur Wellek en Warren. Theory of literature. Penguin 1956, p 84.

20. Volgens Kerenyi, aangehaal deur E Leroux. Die mens, en veral die skrywer op soek na die lewende mite. In Woordwêreld. Lesings van die Afrikaanse studiekring, Stellenbosch. Kaapstad 1963, p 74.

21. Von Wilpert, Op cit, p 691 .

22. B van Vlierden. Van In't Wonderjaer tot De Verwondering. Antwerpen 1969, p 269.

23. Id, p 266.

24. 'Sake' word gebruik soos deur A W de Groot. Inleiding tot de algemene taalwetenschap. Groningen 1964, p 35: "alles waarnaardoor een spreker door middel van een woord verwezen wordt."

25. W K Wimsatt. The verbal icon. London 1970, p 129.

26. K von Delft, Op cit, $p \mathbf{1 0}$

27. Susanne Langer. Problems of art. London 1957, p 132.

28. Vgl A P Grove se bespreking in sy FYN NET VAN DIE WOORD. Kaapstad 1965, p 56.

29. Bespreek deur P Pvan der Merwe, resp in Standpunte 21,3 en 23,2.

30. Deur my behandel in DOLOS EN DENKE. Pretoria 1971, hoofstuk 3.

31. Vgl E Steenberg. Die begrip van die woord 'duister' in die poësie van $N$ P van Wyk Louw. Ongepubliseerde verhandeling, Potchefstroom 1963. 
32. Vgl A P Brink. Die poësie van B Breytenbach. Kaapstad 1971, p 7 .

33. Vgl H du Randt se bespreking vandie gedig in Standpunte26,4, pp 14 e v.

34. Brink, Die poësie van B Breytenbach, p 7.

35. Heidegger, aangehaal deur S Dresden. Existentie-philosophie en literatuurbeschouwing. Amsterdam 1946, p 31.

36. Wellek en Warren. Op cit, p 189. 